\title{
The ABCD rule of dermatoscopy
}

\author{
High prospective value in the diagnosis of doubtful melanocytic skin \\ lesions
}

Franz Nachbar, MD, ${ }^{a}$ Wilhelm Stolz, MD, ${ }^{b}$ Tanja Merkle, MD, ${ }^{a}$ Armand B. Cognetta, MD, ${ }^{c}$ Thomas Vogt, MD, ${ }^{\mathrm{b}}$ Michael Landthaler, MD, ${ }^{\mathrm{b}}$ Peter Bilek, ${ }^{\mathrm{a}}$ Otto Braun-Falco, MD, ${ }^{\mathrm{a}}$ and Gerd Plewig, $\mathrm{MD}^{\mathrm{a}}$ Munich and Regensburg, Germany, and Tallahassee, Florida

\begin{abstract}
Background: The difficulties in accurately assessing pigmented skin lesions are ever present in practice. The recently described ABCD rule of dermatoscopy (skin surface microscopy at $\times 10$ magnification), based on the criteria asymmetry (A), border (B), color (C), and differential structure (D), improved diagnostic accuracy when applied retrospectively to clinical slides.

Objective: A study was designed to evaluate the prospective value of the ABCD rule of dermatoscopy in melanocytic lesions.

Methods: In 172 melanocytic pigmented skin lesions, the criteria of the ABCD rule of dermatoscopy were analyzed with a semiquantitative scoring system before excision.

Results: According to the retrospectively determined threshold, tumors with a score higher than 5.45 (64/69 melanomas [92.8\%]) were classified as malignant, whereas lesions with a lower score were considered as benign (93/103 melanocytic nevi [90.3\%]). Negative predictive value for melanoma (True-Negative $\div$ [True-Negative + False-Negative]) was $95.8 \%$, whereas positive predictive value (True-Positive $\div$ [True-Positive + False-Positive]) was 85.3\%. Diagnostic accuracy for melanoma (True-Positive $\div$ [True-Positive + FalsePositive + False-Negative]) was $80.0 \%$, compared with $64.4 \%$ by the naked eye. Melanoma showed a mean final dermatoscopy score of 6.79 (SD, \pm 0.92 ), significantly differing from melanocytic nevi (mean score, $4.27 \pm 0.99 ; p<0.01, U$ test).

Conclusion: The ABCD rule can be easily learned and rapidly calculated, and has proven to be reliable. It should be routinely applied to all equivocal pigmented skin lesions to reach a more objective and reproducible diagnosis and to obtain this assessment preoperatively.

(J AM ACAD DERMATOL 1994;30:551-9.)
\end{abstract}

Strong efforts to develop diagnostic criteria for early detection of malignant melanoma (MM) have been fueled by the continuing increase in the incidence of MM during the last decades. When compared with clinical criteria alone, ${ }^{1,2}$ skin surface

From the Department of Dermatology, University of Munich, ${ }^{\text {a }}$ The Department of Dermatology, University of Regensburg, ${ }^{b}$ and Dermatology Associates, Tallahassee. ${ }^{\mathrm{c}}$

Supported by a grant of the German Minister of Research and Technology and the Deutsche Forschungsgemeinschaft (Sto 189/1-2).

Presented in part at the Twentieth Annual Meeting of the German Society of Dermatological Research, Nov. 13 to 15, 1992, Mainz, Germany.

Accepted for publication Sept. 7, 1993.

Reprint requests: Franz Nachbar, MD, Department of Dermatology, University of Munich Frauenlobstr. 9-11, D-80337 München, Germany.

Copyright $@ 1994$ by the American Academy of Dermatology, Inc. 0190-9622/94 $\$ 3.00+0 \quad 16 / 1 / 51325$ microscopy produces a significant improvement in diagnostic accuracy of pigmented skin lesions. ${ }^{3-5}$ Until recently, clinical application of skin surface microscopy was hampered because inflexible and expensive stereomicroscopes, which made the technique cumbersome and time consuming, had to be used. $^{3-5}$ These handicaps were overcome with the development of the dermatoscope,${ }^{6}$ which allows rapid surface microscopic investigation. The dermatoscope is a hand-held instrument, similar to an otoscope, with a tubular body that at the top has an achromatic lens focused on a glass footplate providing a skin surface magnification of about $\times 10$. Halogen illumination at an angle of 20 degrees is used with oil or disinfection solution applied to the skin to make the horny layer more translucent. ${ }^{7}$

Numerous criteria in surface microscopy have been described ${ }^{5,8,9}$ that allow experienced observers 
Table I. Algorithm for distinguishing melanocytic and nonmelanocytic pigmented lesions by dermatoscopy

\begin{tabular}{cc}
\hline Pathway steps & Criteria for separation \\
\hline $\begin{array}{c}\text { Easily } \\
\text { identifiable } \\
\text { melanocytic }\end{array}$ & $\begin{array}{c}\text { Pigment network, regular streaks, } \\
\text { brown globules, steel-blue areas } \\
\text { lesions }\end{array}$ \\
$\begin{array}{c}\text { Angiomatous nevus) } \\
\text { tumors and } \\
\text { hemorrhages }\end{array}$ & $\begin{array}{c}\text { Red lakes, homogeneous reddish or } \\
\text { reddish black areas, well-defined } \\
\text { outline, lack of network, regular } \\
\text { streaks and globules }\end{array}$ \\
$\begin{array}{c}\text { Pigmented } \\
\text { Yeborrheic }\end{array}$ & $\begin{array}{c}\text { openings, brownish gray } \\
\text { keratoses }\end{array}$ \\
$\begin{array}{c}\text { appearance, well-defined outline, } \\
\text { lack of network, regular streaks } \\
\text { and brown globules, presence of } \\
\text { teleangiectasias }\end{array}$ \\
Pigmented & $\begin{array}{c}\text { Maple leaf-like areas, } \\
\text { telangiectases, lack of network, }\end{array}$ \\
basal cell & regular streaks and globules \\
carcinomas & Benign and malignant melanocytic \\
Remaining & lesions \\
lesions &
\end{tabular}

Modified from Kreusch J, Rassner G. Hautarzt 1991;42:77-83.

to discriminate between both melanocytic and nonmelanocytic skin lesions and between malignant and benign melanocytic lesions. However, for novices correct interpretation of the images may be difficult to learn. Therefore Stolz et al. ${ }^{10}$ introduced the $A B C D$ rule of dermatoscopy, based on multivariate analysis of only four criteria (asymmetry, abrupt cutoff of the pigment pattern at the border, color variegation, and different structure) with a semiquantitative score system. The rule was developed by a retrospective analysis of color prints of dermatoscopic images at the same magnification seen under the dermatoscope. In the present study we tested the $A B C D$ rule prospectively to see whether determination of the criteria during examination of a lesion accurately predicts the correct diagnosis.

\section{METHODS}

A total of 194 pigmented skin lesions consecutively excised between November 1991 and July 1992 were included. Nonmelanocytic skin lesions were excluded by criteria previously recorded ${ }^{5,8}$ and listed in Table I. Remaining melanocytic lesions were evaluated according to the $A B C D$ rule of dermatoscopy. For the calculation of ABCD score the criteria of asymmetry (A), abrupt cutoff of the pigment pattern at the $b$ order (B), different colors (C), and different structural components (D) were assessed to yield a semiquantitative score. Asymmetry was evaluated with respect to color and structure with perpendicular axes chosen in such a way that the lowest asymmetry score possible is yielded. A score of 0 was given in case of symmetry in both axes, a score of 1 in case of asymmetry in one axis, and a score of 2 in case of asymmetry in both axes (Fig. 1). For the calculation of the border score the lesions were divided into eight segments as shown in Fig. 2. For each segment in which an abrupt cutoff of pigment pattern was present, one point was added to the score. For the color score the number of colors present within the lesion were counted (possible colors: white, red, light and dark brown, blue-gray, and black), leading to a minimum score of 1 and a maximum of 6 (Fig. 3). Possible differential structural componerıs were network, homogeneous areas, dots, globules, and streaks (Fig. 4). ${ }^{5}$ Thus the differential structure score(D) ranged from 1 to 5 points. Finally, the individual scores were multiplied by different weight factors obtained by multivariate analysis. ${ }^{10}$ The weight factors followed by the minimum and maximum scores in parentheses are 1.3 for $\mathrm{A}(0,2.6), 0.1$ for $\mathrm{B}(0,0.8), 0.5$ for $\mathrm{C}(0.5,3.0)$ and 0.5 for $D(0.5,2.5)$. The final $A B C D$ score was calculated by adding the four individual scores ( $A$ through $D$ ), resulting in a minimum final score of $1.0(A=0, B=0$, $\mathrm{C}=1, \mathrm{D}=1)$ and a maximum of $8.9(\mathrm{~A}=2, \mathrm{~B}=8$, $\mathrm{C}=6, \mathrm{D}=5$ ) (Table II).

The results of the retrospective study showed that melanocytic pigmented skin lesions could be differentiated into two diagnostic groups as follows: melanocytic nevi $(\mathrm{MN})$ if the final score was less than 5.45 and $\mathrm{MM}$ if the score was higher than 5.45. Retrospective analysis showed an early melanoma could not be completely excluded in all lesions with an ABCD score between 4.75 and 5.45. Therefore these lesions were excised. All lesions were examined by two independent dermatopathologists.

Sensitivity (True-Positive $\div$ [True-Positive + FalsePositive]), specificity (True-Negative $\div$ [True-Negative + False-Positive]), negative predictive value (True-Negative $\div[$ True-Negative + False-Negative] $)$, positivepredictive value (True-Positive $\div$ [True-Positive + FalsePositive]) and diagnostic accuracy (True-Positive $\div$ [True-Positive + False-Positive + False-Negative]) for both $\mathrm{MM}$ and $\mathrm{MN}$ were assessed to evaluate the predictive value of the $A B C D$ rule. The mean scores of $M N$ and MM were compared by $U$ test $(p<0.01)$ to detect significant statistical differences between the scores. In addition, mean scores of dysplastic nevi, of nevi with signs of inflammation, Spitz nevi, and nevi of the junctional or compound type were calculated as well as mean scores of different types of MM. Pigmented skin lesions to which the $A B C D$ rule was not applied before excision were not included in this study, nor were pigmented skin lesions that were not histologically analyzed. During this study numerous lesions could be clearly classified by dermatos- 

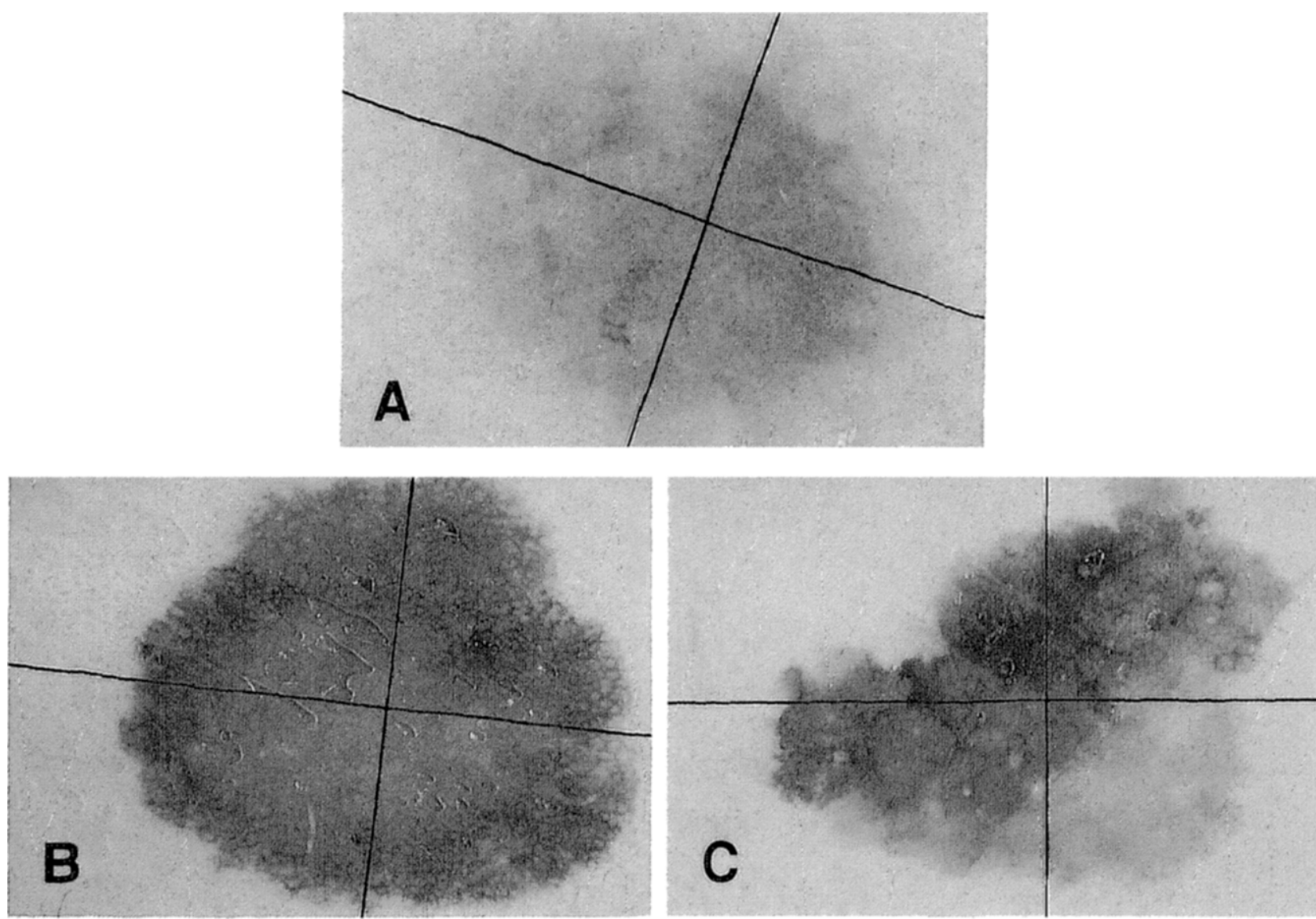

Fig. 1. Evaluation of asymmetry in melanocytic lesions $A$, Lack of asymmetry in both axes (asymmetry score $=0$; compound nevus), $\mathrm{A}=0, \mathrm{~B}=0, \mathrm{C}=2, \mathrm{D}=3 ; \mathrm{ABCD}$ score $=2.5$. B, Asymmetry of lesion in one axis (asymmetry score $=1 ; \mathrm{MM}$ ). $\mathrm{A}=1, \mathrm{~B}=8, \mathrm{C}=3, \mathrm{D}=4$; $\mathrm{ABCD}$ score $=5.6$. $\mathrm{C}$, Asymmetry of lesion in two axes under angle of 90 degrees (asymmetry score $=2 ; \mathrm{MM}) . \mathrm{A}=2, \mathrm{~B}=3, \mathrm{C}=5, \mathrm{D}=4 ; \mathrm{ABCD}$ score $=7.4$.

copy as hemangiomas, seborrheic keratoses, and $\mathrm{MN}$ that were not excised or included in the study. The MN excised and reported here with a score of 4.75 or less were those removed at the patient's request. Pigmented lesions with a score of 4.75 or greater were removed at investigator's advice with a margin of at least $0.5 \mathrm{~cm}$, and these two groups comprise the study set.

Of the 194 cases included, histopathologic investigation revealed $69 \mathrm{MM}, 103 \mathrm{MN}$, and 22 nonmelanocytic lesions. The MM group consisted of 46 superficial spreading melanomas (SSM) (66.7\% of MM), 12 nodular MM (NMM) (17.4\% of MM) and 11 otherwise classified MM (15.9\% of MM). Mean Breslow depth was $1.11 \mathrm{~mm}$ ( $\pm 1.03 \mathrm{SD}$; range, 0.15 to $4.10 \mathrm{~mm}$ ).

The $103 \mathrm{MN}$ were histologically characterized as follows: 21 junctional nevi, 29 compound nevi, 3 combined nevi, 14 dermal or papillomatous nevi, 4 blue nevi, 7 spindle cell or Spitz nevi, 1 desmoplastic nevus, 5 nevi of any type with signs of inflammation, and 19 dysplastic nevi of either the junctional or the compound type according to the criteria of Clark et al. ${ }^{11}$ In comparing the clinical with the dermatoscopic diagnosis with the $\mathrm{ABCD}$ rule it must be noted that all our colleagues in this department referring patients for the study were experienced and in most cases used the dermatoscope without applying the new $\mathrm{ABCD}$ rule. Thus clinical diagnosis in our study was expected to be already biased by the dermatoscopic feature and therefore to be more accurate than by the naked eye.

\section{RESULTS}

Of the 194 lesions, 172 were melanocytic and 22 were nonmelanocytic pigmented lesions histopathologically. In total, 175 pigmented lesions (90.2\%) were correctly diagnosed by dermatoscopy with either the ABCD rule (melanocytic lesions) or characteristic dermatoscopic features (nonmelanocytic lesions), compared with 154 (79.4\%) correct clinical diagnoses. All results are listed in Table III. With the $A B C D$ rule 157 of the 172 histologically proven 

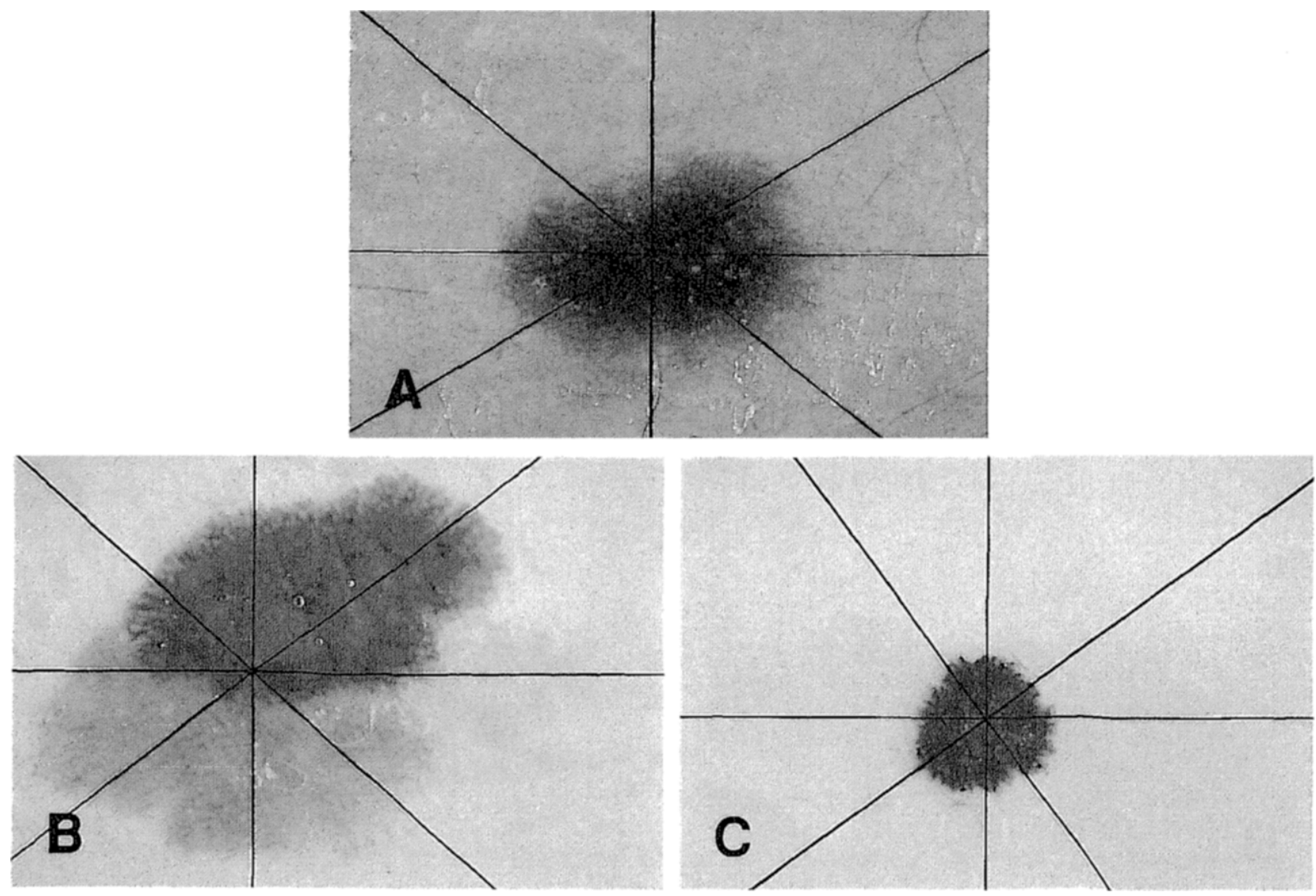

Fig. 2. Evaluation of border in melanocytic lesions. A, Abrupt cutoff of pigment pattern in none of eight segments (border score $=0$; junctional nevus). $A=1, B=0, C=2, D=3$. $\mathrm{ABCD}$ score $=3.8$. $\mathrm{B}$, Abrupt cutoff of pigment pattern in four of eight segments (border score $=4 ; M M) . A=2, B=4, C=4, D=4 ; A B C D$ score $=7.0$. C, Abrupt cutoff of pigment pattern in all eight segments (border score $=8$; Spitz nevus). $\mathrm{A}=0, \mathrm{~B}=8, \mathrm{C}=2$, $\mathrm{D}=3 ; \mathrm{ABCD}$ score $=3.3$.

melanocyticlesions were correctly classified ( $91.3 \%)$, whereas clinical diagnosis was correct in 147 cases $(85.5 \%)$.

According to the ABCD score, sensitivity for MM was $92.8 \%$ (64 true-positive, 5 false-negative), and specificity was $91.2 \%$ (114 true-negative, 11 false-positive). Negative predictive value for $\mathrm{MM}$ was $95.8 \%$ (114 true-negative, 5 false-negative), indicating that with the ABCD rule a melanoma is only rarely missed. Positive predictive value was 85.3\% (64 true-positive, 11 false-positive including $10 \mathrm{MN}$ and one seborrheic keratosis), reflecting a slightly higher rate of false-positive than false-negative figures. Values for sensitivity and specificity, and negative and positive predictive values for $\mathrm{MM}$ with the $A B C D$ rule, were higher than the corresponding values based on the clinical diagnoses; that is, $84.1 \%$ (sensitivity), $83.5 \%$ (specificity), $90.4 \%$ (negative predictive value), and $73.4 \%$ (positive predictive value), respectively. With the dermatoscope diagnostic accuracy for MM was $80.0 \%$ compared with $64.4 \%$ by the naked eye. Distribution patterns of $\mathrm{MM}$ and $\mathrm{MN}$ according to the $\mathrm{ABCD}$ rule of dermatoscopy are illustrated in Fig. 5. Of the $69 \mathrm{MMs}, 64$ had an ABCD score higher than 5.45 and were therefore correctly predicted as MM by the $A B C D$ rule. Five cases of MM were not identified by the $\mathrm{ABCD}$ rule ( $7.2 \%$ false-negative). However, in all these lesions the scores were higher than 4.75, which was considered the threshold for a suspect lesion. Most MMs (35/69) excised in this study were shown histologically to be early malignant lesions (tumor thickness $\leq 0.75 \mathrm{~mm}$, level III or less). Of these 35 early melanomas, 33 (94.3\%) were predicted by the new $A B C D$ rule. None of the MMs was falsely classified as a nonmelanocytic pigmented 

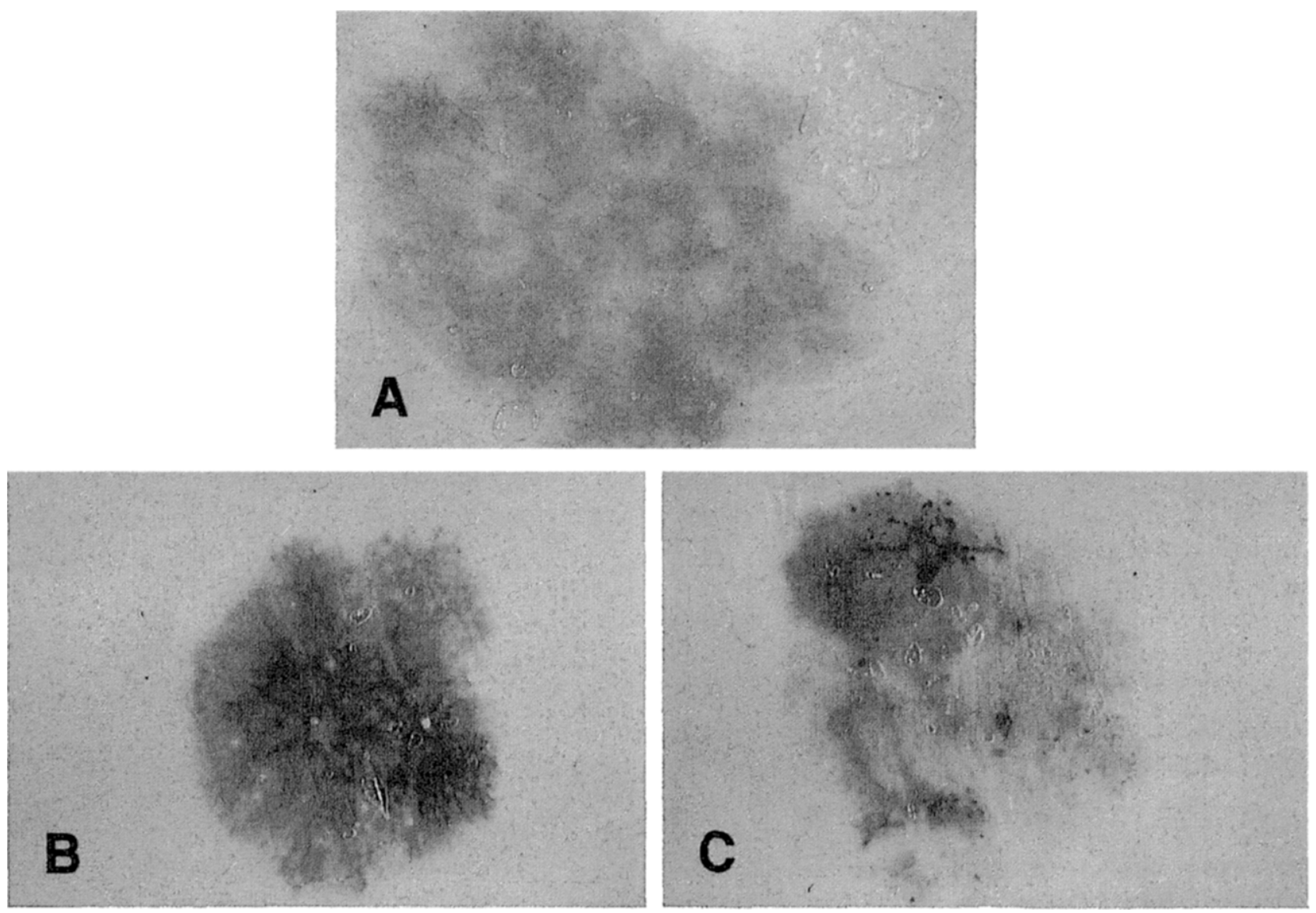

Fig. 3. Evaluation of different colors in melanocytic lesions. A, Two colors (light and dark brown) (color score $=2$; compound nevus.) $\mathrm{A}=0, \mathrm{~B}=0, \mathrm{C}=2, \mathrm{D}=3, \mathrm{ABCD}$ score $=2.5$. $B$, Four colors (light and dark brown, blue-gray, black) (color score $=4 ; M M$ ). $A=1, B=5$, $\mathrm{C}=4, \mathrm{D}=4 ; \mathrm{ABCD}$ score $=5.8$. $\mathrm{C}$, Six colors (white, light and dark brown, blue-gray, red, black) (color score $=6 ; \mathrm{MM}) . \mathrm{A}=2, \mathrm{~B}=0, \mathrm{C}=6, \mathrm{D}=4$; $\mathrm{ABCD}$ score $=7.6$.

lesion by dermatoscopy in contrast to two false clinical diagnoses (seborrheic keratosis, angiokeratoma) in this series.

Clinically $11 \mathrm{MMs}$ were classified as benign lesions (nine MN, one seborrheic keratosis, one angiokeratoma), giving a false-negative rate of $15.9 \%$, compared with a $7.2 \%$ false-negative rate with the use of the $A B C D$ rule.

MNs were correctly assessed by the $\mathrm{ABCD}$ rule in 93 of 103 cases (90.3\%). In all 10 incorrect classifications, the diagnosis of $\mathrm{MM}$ was suspected (ABCD point score $>5.45$ ). Positive predictive value for $\mathrm{MN}$ was $93.9 \%$ and negative predictive value was $89.5 \%$ with the $\mathrm{ABCD}$ rule of dermatoscopy, compared with $88.1 \%$ and $84.9 \%$, respectively, according to the clinical impression. The majority of the false-positive MN $(6 / 10)$ with a final dermatoscopy score higher than 5.45 showed histologic features of dysplastic nevi in three cases, of a nevus with signs of inflammation in one case, and of Spitz nevi in two cases. In the remaining four cases histologic examination disclosed MN of a junctional or compound type.

Mean $\mathrm{ABCD}$ scores of MM and $\mathrm{MN}$ differed significantly $(p<0.01)$ as shown by $U$ test. MM had a mean score \pm SD of $6.79 \pm 0.92$ in contrast to $4.27 \pm 0.99$ for $\mathrm{MN}$. ABCD scores of MM ranged from a minimum of 4.8 (one case; $\mathrm{MM}$ adjacent to a compound nevus; tumor thickness, $0.4 \mathrm{~mm}$ ) to a maximum of 8.8 (NMM; tumor thickness, $3.5 \mathrm{~mm}$ ), whereas scores of benign melanocytic lesions were between 2.0 and 7.0 (Fig. 5). Mean scores of SSM $(6.90 \pm 0.82)$ and NMM $(6.83 \pm 1.21)$ did not disclose significant differences. Mean ABCD scores of dysplastic (4.69 \pm 0.86$)$ and Spitz nevi $(4.66 \pm 1.28)$ and of nevi with signs of inflammation $(4.36 \pm 1.11)$ were found to be higher than the figures of common junctional or compound nevi 

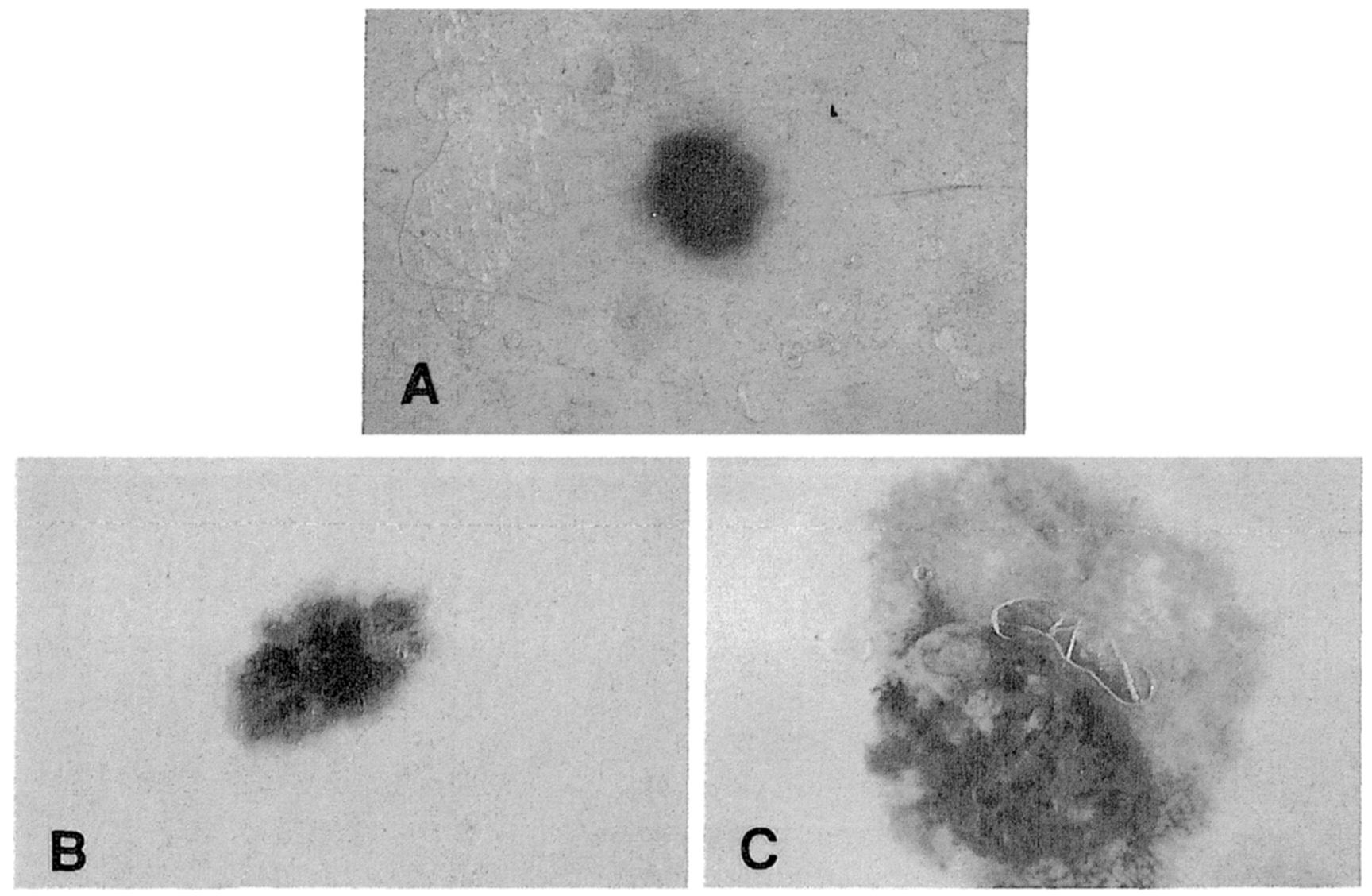

Fig. 4. Evaluation of different structural components in melanocytic lesions. A, One component (homogeneous areas) (differential structure score $=1$; blue nevus). $A=0, B=0$, $\mathrm{C}=2, \mathrm{D}=1 ; \mathrm{ABCD}$ score $=1.5 . \mathrm{B}$, Three components (homogeneous areas, pigment network, streaks) (differential structure score $=3$ junctional nevus). $A=1, B=0, C=3$, $\mathrm{D}=3$; $\mathrm{ABCD}$ score $=4.3$. C, Five components (homogeneous areas, pigment network, streaks, dots, globules) (differential structure score $=5 ; \mathrm{MM}$ ). $\mathrm{A}=2, \mathrm{~B}=2, \mathrm{C}=4, \mathrm{D}=5$; $\mathrm{ABCD}$ score $=7.3$.

Table II. Calculation of ABCD score of dermatoscopy

\begin{tabular}{lcccc}
\hline \multicolumn{1}{c|}{ Criterion } & $\begin{array}{c}\text { Possible } \\
\text { points }\end{array}$ & $\begin{array}{c}\text { Weight } \\
\text { factor }\end{array}$ & $\begin{array}{c}\text { (Score minimum/ } \\
\text { maximum) }\end{array}$ \\
\hline Asymmetry & $0-2$ & 1.3 & $0.0 / 2.6$ \\
$\begin{array}{l}\text { Border (abrupt cutoff } \\
\text { of pigment pattern) }\end{array}$ & $0-8$ & 0.1 & $0.0 / 0.8$ \\
$\begin{array}{l}\text { Colors, different } \\
\text { Different structural }\end{array}$ & $1-6$ & 0.5 & $0.5 / 3.0$ \\
$\quad$ components & $1-5$ & 0.5 & $0.5 / 2.5$ \\
$\begin{array}{l}\text { Final dermatoscopy } \\
\text { score (A to D) }\end{array}$ & & & $1.0 / 8.9$ \\
\hline
\end{tabular}

$(4.17 \pm 0.87)$. Scores ranged in dysplastic nevi from 3.3 to 6.8 , in Spitz nevi from 3.0 to 7.0 , in nevi with signs of inflammation from 2.5 to 5.4 and in junctional or compound nevi from 2.0 to 6.0 . How- ever, the differences were not significant, and ABCD score does not predict different types of nevi.

The 22 histologically proved nonmelanocytic lesions in this study consisted of 19 seborrheic keratoses and three pigmented basal cell carcinomas. Most were clinically suspected to be MM for which these patients were referred to us. With dermatoscopy 15 of 19 seborrheic keratoses $(78.9 \%)$ and all three basal cell carcinomas (100.0\%) were correctly diagnosed (81.8\% of all nonmelanocytic lesions). This was a substantial improvement compared with the clinical impression, by which only seven of 22 nonmelanocytic lesions ( $31.8 \%$ ) were accurately diagnosed.

\section{DISCUSSION}

Three reasons have accounted for the increased attention to skin surface microscopy during the last 
Table III. Comparison between clinical and dermatoscopic diagnoses of pigmented skin lesions

\begin{tabular}{l|c|c|c}
\hline & & \multicolumn{2}{|c}{ No. of correct diagmoses (\%) } \\
\cline { 3 - 4 } \multicolumn{1}{c|}{ Histopathology } & $N$ & $\begin{array}{c}\text { Clinical features and } \\
\text { dermatoscopy without } \\
\text { ABCD rule }\end{array}$ & $\begin{array}{r}\text { ABCD rule of } \\
\text { dermatoscopy }\end{array}$ \\
\hline MM & 69 & $58(84.1)$ & $64(92.8)$ \\
MN & 103 & $89(86.4)$ & $93(90.3)$ \\
Melanocytic lesions (total) & 172 & $147(85.5)$ & $157(91.3)$ \\
Seborrheic keratoses & 19 & $6(31.6)$ & $15(78.9)$ \\
Pigmented basal cell carcinomas & 3 & $1(33.3)$ & $3(100.0)$ \\
Nonmelanocytic lesions (total) & 22 & $7(31.8)$ & $18(81.8)$ \\
Pigmented lesions (total) & 194 & $154(79.4)$ & $175(90.2)$ \\
\hline
\end{tabular}

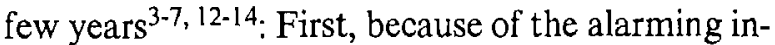
crease in the incidence of MM, reliable methods were necessary to detect early melanoma. Second, survival rate in MM patients strongly correlates with tumor thickness. The lack of effective therapies in patients with thick melanoma and stage II and III disease places early detection as the primary strategy in increasing survival of melanoma patients. Third, clinical investigation of pigmented skin lesions by the naked eye has a maximum diagnostic accuracy of $60 \%$ to $80 \%$ of MM.1, 2,15-18 In November 1989 at the consensus meeting on terminology in surface microscopy of the Committee on Analytical Morphology of the Society for Dermatological Research, numerous dermatoscopic criteria were found to be valuable for discriminating between melanocytic and nonmelanocytic and between benign and malignant melanocytic pigmented lesions. ${ }^{19}$ These criteria are helpful for experienced investigators but difficult to learn for beginners and sometimes also not fully reproducible. To this end multivariate analysis of 31 features from 157 patients with confirned histologic diagnosis was performed to ascertain the most important features. ${ }^{10}$ Four features summarized in the $A B C D$ rule of dermatoscopy to final $A B C D$ score were found to be sufficient for correctly classifying more than $92 \%$ of the pigmented lesions. In the present study the $A B C D$ rule was reexamined prospectively by determining the $\mathrm{ABCD}$ score directly on the patient to evaluate its clinical effectiveness. The most important finding was that more than $90 \%$ of the pigmented melanocytic lesions were correctly identified as benign or malignant with a threshold of 5.45. All melanomas displayed an ABCD score higher than 4.75, which was considered a threshold for suspected lesions. Patients were advised to have an cxcision of lesions from this value upward with a margin of at least $0.5 \mathrm{~cm}$. The 4.75 -point threshold was confirmed in this study because no melanoma showed a lower score. However, further data are required for a definite assessment of the optimum threshold value.

Use of the $A B C D$ rule was not only sensitive in detecting $\mathrm{MM}$ but also more specific in accurately classifying both $\mathrm{MM}$ and $\mathrm{MN}$ compared with conventional clinical diagnosis with the naked eye. According to a retrospective study of Grin et al., ${ }^{1}$ the clinical accuracy in diagnosing $\mathrm{MM}$ was reported to be $62.2 \%$ in 265 histologically proved MM during a period of 27 years (computerized data base of the Oncology Section, Skin Cancer Unit of New York), whereas our data confirm that a correct classification of more than $90 \%$ of $\mathrm{MM}$ is achievable by the $A B C D$ rule of dermatoscopy. On the other hand, difficulties in correctly distinguishing between clinically equivocal lesions such as Spitz or dysplastic nevi and MM were occasionally also present with the use of the $A B C D$ rule. In some of these cases, however, histologic findings were also ambiguous.

In our study the clinical classification rate was higher than in previous studies. ${ }^{1,2,15-18}$ This was because clinical diagnosis often was enhanced by dermatoscopy performed in our outpatient clinic but not with application of the ABCD rule. It is noteworthy that numerous histologically proved $\mathrm{MM}$ with ABCD scores higher than 5.45 were early MM.

Analysis of melanocytic lesions misclassified by the $A B C D$ rule reveals that three types of $M N$ have to be viewed with caution: (1) Three of 10 false-positive MN showed histologic features of dysplastic nevi. Because clear differentiation between dysplastic nevi and initial MM is sometimes also difficult histologically, it is not surprising that these cause 


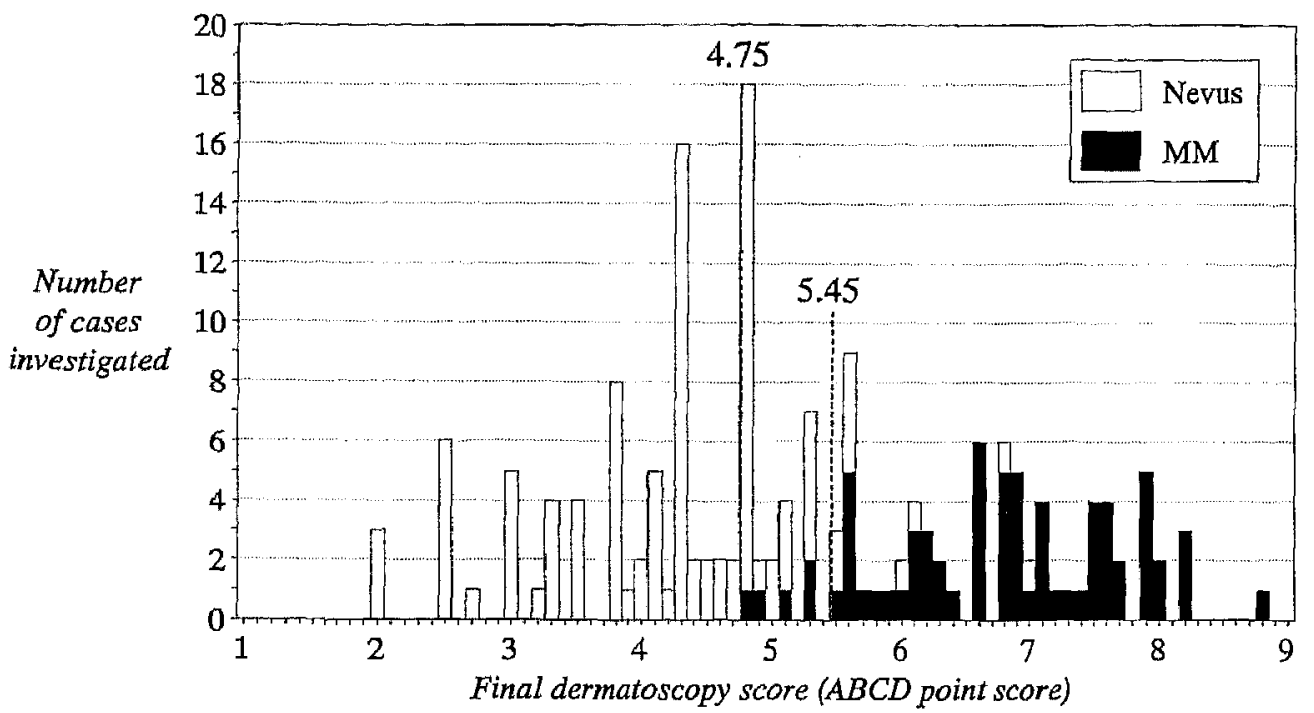

Fig. 5. Classification of cases according to $A B C D$ score of dermatoscopy $([$ Asymmetry $\times 1.3]+[$ Abrupt Cutoff at Border $\times 0.1]+[$ Different Colors $\times 0.5]+[$ Differential Structure $\times 0.5]$ ).

errors in dermatoscopic diagnosis. (2) Two of seven Spitz nevi were also misclassified as MM. These lesions can be regularly identified by a prominent symmetric starburstlike appearance of the pigment pattern that stops abruptly at the border. ${ }^{5}$ However, in some cases they might be asymmetric and higher than 5.45 ABCD scores can then be possible. (3) Benign nevi with signs of inflammation or traumatization (of any type) infrequently exhibited $\mathrm{ABCD}$ scores of more than $4.75(3 / 5)$ and $5.45(1 / 5)$. Manipulations such as scratching may affect symmetry as well as color and differential structures within the lesion. In these patients history can be of further help in diagnosis.

Failure to diagnose MM occurred in five lesions including two NMM, two SSM, and one early MM adjacent to a nevus. The two undiagnosed NMM did not express asymmetry in two axes, color variegation, or numerous different structural components, and thus $A B C D$ scores were less than 5.45 (4.9 and 5.3, respectively). A thick NMM with a lower mean ABCD score may be explained by the inability to illuminate structures deep below the surface with the dermatoscope. In addition, two SSM and one MM adjacent to a nevus were incorrectly classified as $\mathrm{MN}$. However, retrospective analysis of the slides did not disclose criteria for MM.

Regardless of the difficulties in these cases, use of the dermatoscopic $A B C D$ rule in this study facili- tated differential diagnosis between benign and malignant melanocytic lesions, as compared with clinical diagnosis. Moreover, our diagnostic accuracy rates were compared with those of earlier investigators who used expensive, cumbersome, and timeconsuming stereomicroscopes. ${ }^{3-5}$

Aside from this, our results reconfirm previous reports that dermatoscopy frequently enables correct differentiation between nonmelanocytic and melanocytic lesions that were ambiguous to the naked eye. ${ }^{4,8}$ Correct differentiation between melanocytic and nonmelanocytic lesions was achieved in 192 of 194 lesions by dermatoscopy (compared with only 176 by clinical features alone). Rate of accurate preoperative diagnosis of nonmelanocytic lesions was twice as high by dermatoscopy as by the naked eye. The overall results would have been even better if equivocal clinical lesions that on dermatoscopy were shown to be hemangiomas, thrombosed angiomas, angiokeratomas, or seborrheic keratoses had been removed.

Although diagnostic accuracy could be signifcantly increased by use of the dermatoscope, the scores obtained always had to be juxtaposed with the patient's history and clinical features. In our hands the $A B C D$ rule has been proved to be useful in (1) early detection of $\mathrm{MM},(2)$ discrimination between benign and malignant lesions, (3) selection of lesions for excision in patients with numerous atypically appearing nevi, and (4) monitoring of certain MN 
that for cosmetic or patient preference were not removed.

The future refinement and expanded use of dermatoscopy may one day bring us to a point at which unnecessary surgical removal of benign lesions will be avoided and appropriate management of malignant lesions will be instituted before the initial biopsy.

\section{REFERENCES}

1. Grin CM, Kopf AW, Welkovich B, et al. Accuracy in the clinical diagnosis of malignant melanoma. Arch Dermatol 1990;126:763-6.

2. Cassileth BR, Clark WH Jr, Lusk EJ, et al. How well do physicians recognize melanoma and other problem lesions? J AM ACAD DERMATOL 1986;14:555-60.

3. Soyer HP, Smolle J, Kresbach H, et al. Zur Auflichtmikroskopie von Pigmenttumoren der Haut. Hautarzt 1988;39:223-7.

4. Steiner A, Pehamberger $H$, Wolff $K$. In vivo epiluminescence microscopy of pigmented skin lesions. II. Diagnosis of small pigmented skin lesions and early detection of malignant melanoma. J AM ACAD DERMATOL 1987;17:584-91.

5. Pehamberger $H$, Steiner A, Wolff $K$. In vivo epiluminescence microscopy of pigmented skin lesions. I. Pattern analysis of pigmented skin lesions. J AM ACAD DERMATOL 1987;17:571-83.

6. Stolz W, Bilek P, Landthaler M, et al. Skin surface microscopy. Lancet 1989;2:864-5.

7. Braun-Falco O, Stolz W, Bilek P, et al. Das Dermatoskop. Hautarzt 1990;41:131-6.

8. Kreusch J, Rassner G. Standardisicrte auflichtmikrosko- pische Unterscheidung melanozytischer und nichtmelanozytischer Pigmentmale. Hautarzt 1991;42:77-83.

9. Kreusch J, Rassner G. Strukturanalyse melanozytischer Pigmentmale durch Aullichtmikroskopie. Hautarzt 1990; $41: 27-33$.

10. Stolz W, Hölzel D, Riemann A, et al. Multivariate analysis of criteria given by dermatoscopy for the recognition of melanocytic lesions. In: Book of Abstracts, Fiftieth Meeting of the American Academy of Dermatology, Dallas, Tex: Dec. 7-12, 1991.

11. Clark WH Jr, Elder DE, Guerry D, et al. The precursor lesion of superficial spreading and nodular melanoma. Hum Pathol 1984;15:1147-65.

12. MacKie R. An aid to the preoperative assessment of pigmented lesions of the skin. Br J Dermatol 1971;85:232-8.

13. Fritsch $P$, Pechlaner R. Differentiation of benign from malignant melanocytic lesions using incident light microscopy. In: Ackerman AB, ed. Pathology of malignant melanoma. New York: Masson, 1981:301-12.

14. Soyer HP, Smolle J, Kerl H. Early diagnosis of malignant melanoma by surface microscopy. Lancet 1987;2:803.

15. Rampen FH, Rumke P. Referral pattern and accuracy of clinical diagnosis of cutaneous melanoma. Acta Derm Venereol (Stockh) 1988;68:61-4.

16. Kopf AW, Mintzis M, Bart RS. Diagnostic accuracy in malignant melanoma. Arch Dermatol 1975;11 1:1291-2.

17. Koh HK, Lew RA, Prout MN. Screening for melanoma / skin cancer: theoretic and practical considerations. J AM ACAD DERMATOL 1989;20;159-72.

18. Schmoeckel C, Wagner-Grösser G, Braun-Falco O. Klinische Diagnostik initialer maligner Melanome. Hautarzt 1985;36:558-62.

19. Bahmer FA, Fritsch P, Kreusch J, et al. Terminology in surface microscopy. J AM ACAD DERMA TOL 1990;23:115962. ume 31 (July-December). Shipping charges are included. Each bound volume contains a subject and author index and all advertising is removed. Copies are shipped within 60 days after publication of the last issue in the volume. The binding is durable buckram with the journal name, volume number, and year stamped in gold on the spine. Payment must accompany all orders. Contact Mosby-Year Book, Inc., Subscription Services, 11830 Westline Industrial Dr., St. Louis, MO 63146-3318. USA: phone (800) 453-4351; (314) 453-4351.

Subscriptions must be in force to qualify. Bound volumes are not avatlable in place of a regular journal subscription. 